Running Head: DROPOUT AMONG IPV PERPETRATORS

Dropout among Perpetrators of Intimate Partner Violence Attending an Intervention Program

Olga Cunha ${ }^{\mathrm{a}}$, Andreia Silva ${ }^{\mathrm{b}},{\text { Ana Rita } \mathrm{Cruz}^{\mathrm{c}} \text {, Andreia de Castro Rodrigues }}^{\mathrm{d}}$, Teresa Braga $^{\mathrm{e}}$ and Rui Abrunhosa Gonçalves ${ }^{\mathrm{b}}$

${ }^{\text {a }}$ Lusófona University, Porto, Portugal, Hei Lab

${ }^{\mathrm{b}}$ University of Minho, Braga, Portugal, Psychology Research Centre (CIPsi)

${ }^{\mathrm{c}}$ Lusófona University, Lisbon, Portugal, Hei Lab

${ }^{\mathrm{d}}$ ISPA - University Institute, Lisboa, Portugal, William James Center for Research

e Integration and Probation Penitentiary Services, Laon, Aisne, France

Correspondence concerning this article should be addressed to Olga Cunha, Faculty of Psychology, Education, and Sports, Lusófona University of Porto, Rua Augusto Rosa, 24, 4000-098, Porto, Portugal.

E-mail address: olga.cunha@ulp.pt

Biographical notes

Olga Cunha, PhD, is an assistant professor at the Faculty of Psychology, Education, and Sports, Lusófona University, Porto, Portugal, and a researcher at the Hei Lab:

Digital Human-Environment Interaction Lab.

Andreia Silva, Master, is a researcher at the Psychology Research Centre (CIPD), School of Psychology, University of Minho, Braga, Portugal; 
Ana Rita Cruz, PhD, is an assistant professor at School of Psychology and Life Sciences, Lusófona University, Lisbon, Portugal, and a researcher at the Hei Lab: Digital HumanEnvironment Interaction Lab.

Andreia de Castro Rodrigues, $\mathrm{PhD}$, is an assistant professor at ISPA - University Institute (Lisboa), Portugal and a researcher at the William James Center for Research.

Teresa Braga, $\mathrm{PhD}$, is a psychologist at Integration and Probation Penitentiary Services, Aisne, France. The views and opinions expressed in this article are those of the author and do not necessarily reflect the official policy or views of the Integration and Probation Penitentiary Services of France.

Rui Abrunhosa Gonçalves, PhD, is an associate professor at the School of Psychology, University of Minho, Portugal, and a researcher at Research Center on Psychology (CIPsi).

This study was conducted at Psychology Research Centre (UID/PSI/01662/2013), University of Minho, and supported by the Portuguese Foundation for Science and Technology and the Portuguese Ministry of Science, Technology and Higher Education through national funds and co-financed by FEDER through COMPETE2020 under the PT2020 Partnership Agreement (POCI-01-0145-FEDER-007653). The study was also supported by Grant SFRH/ BD/66110/2009 from the Portuguese Foundation for Science and Technology awarded to the first author.

This article has been accepted for publication in Psychology, Crime \& Law, published by Taylor \& Francis. 
Running Head: DROPOUT AMONG IPV PERPETRATORS

\section{Dropout among Perpetrators of Intimate Partner Violence Attending an Intervention}

\section{Program}

Batterer intervention programs (BIPs) are one of the most relevant strategies to reduce intimate partner violence (IPV). However, the rates of dropout are significantly high, which may impact the effectiveness of such strategies. Literature has identified several factors associated with BIP dropout; nonetheless findings remain inconsistent. The aims of this study were to analyze the differences between perpetrators who completed the program and those who droped out, in terms of sociodemographic, violence-related and intrapersonal variables, as well as identify the predictors of dropout. 83 IPV perpetrators completed a set of measures that assessed attitudes toward domestic violence, physical and psychological abuse of a partner, aggression, coping skills, and readiness to change. Variables related to past criminal history and sociodemographics were also colletected. $42.2 \%$ of IPV perpetrators failed to complete the intervention program. The results revealed that age and previous convictions by other crimes than IPV discriminated perpetrators who completed the program from those who droped out, such that, being young and having a previous conviction predicted dropout. These findings reveal a need to further analyze the impact of these factors so BIPs can be tailored to meet the specificities of IPV perpetrators and prevent treatment dropout.

Keywords: Batterer Intervention Programs, Dropout, Intimate Partner Violence, Perpetrators.

\section{Introduction}


Running Head: DROPOUT AMONG IPV PERPETRATORS

Intimate partner violence (IPV) is a major public health issue which occurs in all settings and among all socioeconomic and cultural groups (World Health Organization [WHO], 2012). It is frequently associated with physical, mental, and social consequences to the victims, their families, and the community (e.g., Bacchus et al., 2018; Vilariño et al., 2018). Although results from different studies and meta-analyses suggest that both men and women can perpetrate IPV (e.g., Archer, 2000; Strauss, 2011), research has shown that men are the most common perpetrators and often perpetrate the most serious acts of physical violence against female partners (e.g., Archer, 2000; Straus, 2011; WHO, 2012).

The scientific community, professionals, and public administrators have been looking for more effective strategies to prevent and reduce violence against women in intimacy. As a consequence, different social and legal measures have been developed. Intervention programs for perpetrators of IPV are one of these measures (e.g., Cannon et al., 2016; Cunha \& Gonçalves, 2014; Ferrer-Perez \& Bosch-Fiol, 2016; Gover et al., 2011; Scott et al., 2011). In many countries, the referral of individuals convicted for IPV for batterer intervention programs (BIPs) by the court works as an alternative measure to imprisonment (Dalton, 2007), or as an injunction (Cannon et al., 2016). These programs aim to promote behavioural, attitudinal and cognitive change in perpetrators and to reduce IPV risk of revictimisation/recidivism (e.g., Babcock et al., 2011; Coulter \& VandeWeerd, 2009).

Despite the expansion of BIPs, its effectiveness in reducing future incidents of IPV remains controversial. Although several studies have revealed benefits for men who complete intervention programs, such as, significant reduction in abusive behaviours (e.g., Catlett et al., 2010; Cunha \& Gonçalves, 2015; Lila et al., 2020), in the risk of future violence (e.g., Coulter \& VandeWeerd, 2009; Lauch et al., 2017), in psychopathology (Cunha \& Gonçalves, 2015), in attitudes that tolerate IPV (e.g., Cunha \& Gonçalves, 2015; Lila et al., 2020), and an increase in self-esteem and problem-solving skills (Cunha \& Gonçalves, 2015), the results of 
Running Head: DROPOUT AMONG IPV PERPETRATORS

meta-analyzes remain inconsistent. Some studies concluded that BIPs have reduced effects on IPV's cessation and recidivism rates (Arias et al., 2013; Babcock et al., 2004; Feder \& Wilson, 2005); others point to a significant effect of BIPs in reducing violence (Karakurt et al., 2019); while others revealed an effective decrease on IPV recidivism when reported by the criminal justice system, but not when assessed by the survivor (Cheng et al., 2019). Despite these inconsistencies, the literature recognises the importance of continuing to integrate perpetrators into these programs, since this small effect may be significant for the victims (Babcock et al., 2004; Ferrer-Perez \& Bosch-Fiol, 2016). Moreover, studies agree on the importance of improving BIPs in order to increase their effectiveness (e.g., Lila et al., 2018).

Research has consistently shown that one of the main problems of BIPs is the high rates of dropout (e.g., Cunha \& Gonçalves, 2014; Jewell \& Wormith, 2010), which justify the growing concern with this phenomenon and raise serious questions regarding these intervention programs (Ferrer-Perez \& Bosch-Fiol, 2016). The non-completion of programs designed to reduce recidivism is considered a significant obstacle for treatment success (e.g., McMurran et al., 2010), having potentially severe implications for client welfare and public safety (Olver et al., 2011): first, dropout is a predictor of IPV re-assault (e.g., Bennett et al., 2007; Carney et al., 2006; Gondolf, 2000; Lauch et al., 2007; Lila et al., 2019; Olver et al., 2011); second, many variables that predict treatment dropout also predict IPV recidivism (e.g., Cattaneo \& Goodman, 2005; Hanson \& Wallace-Capretta, 2004; Stith et al., 2004) as well as general recidivism (e.g., Eisenberg et al., 2019; Gendreau et al., 1996). Thus, it is crucial to understand offender's characteristics associated with dropout to identify individuals who may be more likely to dropout from treatment (e.g., Askeland \& Heir, 2013; Jewell \& Wormith, 2010; Olver et al., 2011). 
Several studies have been conducted to identify factors that predict IPV treatment dropout. Typically, studies focused on four broad categories of variables: (1) sociodemographic variables, such as age, education, and socioeconomic level; (2) violencerelated variables, such as severity and frequency of violence, and criminal history (e.g., previous arrests, source of referral); (3) intrapersonal characteristics, including personality and/or clinical disorders, substance use/abuse, relationship indicators (e.g., hostility, anger) and motivation; and (4) external factors, including intervention program, session fees, program length, distance travelled to participate in the program and external monitoring (e.g., Daly \& Pelowski, 2000; Jewell \& Wormith, 2010; Olver et al., 2011). However, the findings that emerge from the different studies are mixed (see Daly \& Pelowski, 2000 for a review).

Regarding sociodemographic variables, literature revealed that younger, unemployed, and single perpetrators, belonging to a racial/ethnic minority, less educated, and with a lower income tend to be more likely to dropout from intervention (e.g., Askeland \& Heir, 2013; Blatch et al., 2020; Cantos et al., 2015; LaPosta et al., 2019; Timko et al., 2015). On the opposite, older, employed, married, Caucasian, with higher income, and more educated perpetrators (e.g., Askeland \& Heir, 2013; Bowen \& Gilchrist, 2006; Catlett et al., 2010; Gover et al., 2011) demonstrate lower dropout rates. Concerning violence-related variables, different studies found that individuals who dropout tend to have more extensive criminal records (e.g., prior arrests and/or convictions; Bennett et al., 2007; Bowen \& Gilchrist, 2006; Cantos et al., 2015; Richards et al., 2019). Nonetheless, other studies pointed that treatment completers have more prior arrests and/or convictions (Dalton, 2001; Daly et al., 2001). Research also reveal that court-mandated perpetrators are more likely to complete treatment than self-referred ones (Barber \& Wright, 2010; Cannon \& Ferreira, 2017; Lauch et al., 2017), however, findings are mixed on whether referral source predicts dropout (e.g., Dalton, 2001). Being victim of abuse and/or witnessing violence in the family of origin is also related 
Running Head: DROPOUT AMONG IPV PERPETRATORS

to treatment dropout (Chang \& Saunders, 2002), although other studies do not support these conclusions (Bowen \& Gilchrist, 2006; Daly et al., 2001; Priester et al., 2019). The severity of abuse was also found as a predictor for treatment dropout, with men who inflict more severe violence against their intimate partner being at a greater risk to abandon treatment (Carney et al., 2006; Rooney \& Hanson, 2001). Among intrapersonal characteristics, alcohol and drug use are correlated with treatment dropout (e.g., Bowen \& Gilchrist, 2006; Cantos et al., 2015; Dalton, 2001; Lila et al., 2020; LaPosta et al., 2019; Romero-Martínez et al., 2019), and higher levels of anger with treatment completion (e.g., Bowen \& Gilchrist, 2006; Chang \& Saunders, 2002). Concerning motivation, results are mixed. While some studies reported that low motivation is related with dropout (e.g., Bennett et al., 2007; Pearson et al., 2020), others suggest that the stage of change was not related with intervention completion (e.g., Mach et al., 2017). Although only a few studies assessed the role of external factors on perpetrators' dropout (e.g., Gondolf \& Foster, 1991; DeHart et al., 1999; Timko et al., 2015), it was found that men who paid more fees were more likely to attend more sessions. Besides, participants who attended shorter programs were more likely to complete the intervention than participants who attended longer programs (Cissner \& Puffett, 2006). Other studies found that the theoretical orientation of the treatment program was an important moderating variable of dropout, with Duluth/CBT programs revealing lower dropout rates (e.g., Jewell \& Wormith, 2010; Zarling et al., 2017). Furthermore, a recent meta-analysis conducted by Santirso et al. (2020) revealed that IPV interventions that incorporated motivational strategies were significantly more effective in increasing the intervention dose and reducing dropout than interventions without motivational strategies.

Two meta-analyses were performed to clarify the former inconsistencies, providing a more comprehensive perspective on the ability of different factors to predict attrition (e.g., Jewell \& Wormith, 2010; Olver et al., 2011). These meta-analyses concluded that several 
Running Head: DROPOUT AMONG IPV PERPETRATORS

variables distinguish treatment completers from dropouts. The most significant factors were employment, age, income, education, professional status, marital status, race/ethnicity, referral source, previous IPV offences, criminal history, exposure to family violence in childhood, alcohol and drug use, personality and/or clinical disorders, anger, treatment engagement and motivation (e.g., Jewell \& Wormith, 2010; Olver et al., 2011).

\section{Batterer intervention programs (BIPs) in Portugal}

In Portugal, the penal code prior to 1974 (a dictatorship) did not contemplate crimes against partners and/or ex-partners, and only in 1982 IPV was criminalized for the first time. After that, different legal diplomas, and National Plans Against Domestic Violence introduced legislative, political, and social changes. In 1998 maltreatment became a semi-public crime, and in 2000 it became a public crime; in 2007, IPV was extended to same-sex relationships, and BIPs were considered as a possible additional penalty; in 2013, the crime was extended to dating relationships, and BIPs became mandatory (Cunha \& Gonçalves, 2015). Besides, the III National Plan Against Domestic Violence 2007-2010 (Resolution of the Council of Ministers no. 83/2007) contemplated the implementation of prevention programs with offenders to avoid repeated offending for the first time.

In spite of social and legal advances and the high number of domestic crimes reported to the police in Portugal (in 2020, among our 10.3 million inhabitants, 23,439 crimes were reported to the police; Sistema de Segurança Interna, 2021), BIPs are very recent. The first interventions with batterers were implemented in the 1990s (e.g., Manita, 2008); but only in 2009, structured BIPs appeared. So far, there are only a few batterer's programs in the Portuguese context. The "Contigo" Program (e.g., Marques et al., 2019; Rijo \& Capinha, 2012), the Program for Aggressors of Domestic Violence (PAVD; Quintas et al., 2012; Rijo \& Capinha, 2012) and the Promotion and Intervention Program with Batterers (PPRIAC; 
Running Head: DROPOUT AMONG IPV PERPETRATORS

Cunha \& Gonçalves, 2015) are three examples of BIPs, which revealed positive results in terms of efficacy with completion rates between $71.4 \%$ (Quintas et al., 2012) and 77.5\% ("Contigo" Program; Marques et al., 2019). In this study we will focus on the PPRIAC program.

\section{The Current Study}

This study aimed to examine the differences between individuals who completed the intervention program and those who droped out, in terms of sociodemographic, violencerelated and intrapersonal variables, using pre-treatment assessment scores in a sample of court- and self-referred men who attend a BIP - the PPRIAC. It is also intended to identify dropout predictors.

The PPRIAC was developed in 2010 at the University XX. This program was intended for self- or court-referred adult male perpetrators who wanted and/or were required to change their abusive behavior against their current or former intimate partner. Participants had to be able to read and write and should not present psychotic disorders, cognitive impairment, psychological and/or personality disorders, and/or substance abuse. The focus of the intervention was to end violence against the intimate partner and to promote batterer's personal and social skills (Cunha \& Gonçalves, 2015). The main goals of the BIP were: (a) to stop the abusive behavior and to promote victim's safety; (b) to accept responsibility for the abusive behavior; (c) to change irrational beliefs and attitudes toward marital violence; (d) to promote respect for women and healthy relationships; (e) to acquire personal and social skills; and (f) to promote a violence-free approach in problem-solving. The program adopted a multilevel - comprising four to six individual sessions and 18 group sessions - and a multimodal approach, using Motivational Interview and cognitive-behavioural and psychoeducational techniques. The individual sessions, of 60 min each, were part of the 
screening, diagnosis, and motivational approach phase, and the group sessions, of 90 to 120 min each, were part of the psychoeducational and behavioral control phase. The sessions occurred weekly and were facilitated by two therapists.

Although considerable research has been conducted to identify factors that predict BIPs droupot, most of the studies were conducted in North America; therefore their relevance to batterers treated in other contexts remains ambiguous. Moreover, in Portugal, to the best of our knowledge, there are no studies assessing variables related to treatment dropout. The identification of such variables is of great importance in the Portuguese context for two reasons: BIPs assessed revealed dropout rates between 23\% and 29\% (Cunha \& Gonçalves, 2015; Marques et al., 2019; Quintas et al., 2012); and the identification of variables related to dropout can allow the development of more appropriate and effective intervention programs, and, thus, protect the victims and prevent future incidents of IPV (e.g., Cuevas \& Bui, 2016; Daly \& Pelowski, 2000; Gover et al., 2011).

The present study is also innovative since, although typical literature within this field has mainly focused on men under court order for treatment (Daly \& Pelowski, 2000; Jewell \& Wormith, 2010), in this study both court-ordered and self-referred batterers were included. By not focusing exclusively on court-ordered individuals, the potential effects of referral source can be analyzed. Besides, in the present study intrapersonal variables that have not been frequently studied in male batterers, such as motivation, attitudes toward intimate partner violence, or coping skills (Daly \& Pelowski, 2000; Wormith \& Olver, 2002) were included in order to understand their impact on treatment dropout.

\section{Method}

\section{Participants}

Participants were recruited based on a process of convenience sampling. The present study included 83 male IPV perpetrators who were enrolled in the PPRIAC. Participants were, on 
average, 46.38 years old $(S D=11.74)$, ranging from 23 to 75 years, mainly Caucasians $(\mathrm{n}=$ 82, 98.8\%). Almost half of the participants were married or cohabited with the victim at the time of the intervention $(n=41 ; 49.4 \%)$ and the length of the relationship ranged from a minimum of six months to a maximum of 50 years $(M=19.06, S D=12.28)$. Most of the participants completed 9 years of education $(n=60 ; 72.3 \%)$, belonged to low $(n=3947 \%$; $n$ $=39$ ) or medium $(n=36 ; 43.4 \%)$ socioeconomic status (SES) and almost an half was employed $(n=41 ; 49.4 \%)$. More than half of the participants were court-ordered to the intervention program $(n=54 ; 65.1 \%), 14.5 \%(n=12)$ had prior convictions for crimes other than IPV, and 4.8\% $(n=4)$ had also been previously convicted of IPV. Table 1 summarizes the main sociodemographic and violence-related variables.

\section{[INSERT HERE TABLE 1]}

\section{Measures}

Dropout. BIP dropout was measured as a categorical variable capturing treatment completers and dropouts. Dropouts included individuals who completed the intake assessment but failed to attend more than $25 \%$ of the sessions. Treatment completers included participants who completed the intake assessment and at least $75 \%$ of the treatment sessions.

Demographic variables. Demographic information was collected through a brief questionnaire assessing age, relationship length, marital status, socioeconomic status, education grade, professional status, and race.

Violence-related variables. Criminal history (e.g., prior convictions for IPV and for other crimes) and referral source (court- or self-referred) were assessed through a questionnaire developed for this study. When available, perpetrators' files were also analyzed.

IPV frequency was assessed using the Marital Violence Inventory (IVC; Machado et al., 2007). It is a 21-item inventory, reporting physically abusive behavior, emotionally abusive behavior, and coercion/intimidation behavior, scored in a 3 -point scale $(0=$ never, 1 
$=$ once, $2=$ more than once). Items are grouped along two scales (Physical Violence and Psychological Violence) and a total score of the frequency of violence. In this study, the internal consistency for the total scale was .87 , and .86 and .70 for physical and psychological violence scales, respectively.

Intrapersonal variables. Intrapersonal information was collected through a series of psychological self-report questionnaires, fulfilled in the pre-treatment assessment.

The Buss-Perry Aggression Questionnaire (BPAQ; Buss \& Perry, 1992) is a selfreport instrument constituted by 29 items evaluated on a scale of 5 points, ranging from 1 (extremely uncharacteristic of me) to 5 (extremely characteristic of me). It is composed of four subscales: Physical Aggression, Verbal Aggression, Anger, and Hostility. The internal consistency values vary from .72 and .85 , concerning the four subscales, and .89 for the total scale. In this sample, the internal consistency for the total score was of .86, and ranges between .50 (hostility) to .76 (anger) for the different scales.

The Attitudes Toward Marital Violence Scale (ECVC; Machado et al., 2007) is a 25item scale, coded in a 5-point scale, ranging from 1 (completely disagree) to 5 (completely agree), and assesses attitudes toward IPV. Factorial analysis revealed four factors: Legitimation and Minimization of Minor Violence, Legitimation of Violence Due to Women's Behavior, Legitimation of Violence Due to External Causes, and Legitimation of Violence Due to Family Privacy. A higher score means attitudes supporting IPV. The correlation between each factor and the total score varies between .34 and .71 , and the internal consistency for the total score is .93 (Machado et al., 2007). In the present study, the internal consistency for the total score is .92 .

The Problem-Solving Inventory (IRP; Serra, 1987) is a multidimensional scale to assess coping strategies. The inventory is composed of 40 items, coded on a 5-point Likerttype scale, ranging from 1 (not agree) to 5 (agree very much). It presents a total score and 
nine factors: Request for Help, Confrontation and Active Problem Solving, Passive Abandonment at the Situation, Internal/External Control of the Problems, Strategies of Emotions' Control, Active Attitude of Non-Interference in Everyday Life by Occurrences, Internalized/Externalized Aggression, Self-Accountability and Fear of Consequences, and Confronting the Problems and Planning Strategies (Serra, 1987). The higher the score, the better the coping strategies used by the individual. The inventory showed temporal stability, with a test-retest correlation of .81 and internal consistency of .86. In the present study, the internal consistency for the total scale was of .78. The alphas for the nine scales ranged between .43 (Self-Accountability and Fear of Consequences) and .71 (Passive Abandonment at the Situation).

The University of Rhode Island Change Assessment Scale-Domestic ViolenceRevised (URICA-DV-R) (Levesque et al., 2000) is a self-report scale that assesses the stages of change according to the Transtheoretical Model. URICA-DV-R assesses men's readiness to change violent behavior toward their intimate partners. It is composed of 20 items answered on a 5-point Likert-type scale $(1=$ strongly disagree until $5=$ strongly agree $)$. The scale discriminates four stages of change: Precontemplation, Contemplation, Action and Maintenance. The instrument also provides a global Readiness of Change Index. Scaled scores for each stage dimension are calculated by taking the unweighted sum of the five items representing each dimension and converting those scores into standard T-scores (Levesque et al. 2000). Levesque et al. (2000) reported internal consistency ranging from .68

(Maintenance) to .81 (action). In the present sample, the internal consistency ranged from .45 for the Precontemplation scale to .83 for the Contemplation scale.

\section{Procedure}

The sample of the present study is composed of individuals who participated in the PPRIAC. The program was delivered in two differente settings: the Unit of Justice and Community 
Running Head: DROPOUT AMONG IPV PERPETRATORS

Psychology of the XX Psychology Service and a family-support institution in the North of Portugal. Participants were referred to the intervention by the court, child protection services, victim-support and family-support institutions, probation services or were self-referred. Potential participants were subjected to a screening interview. All the procedures were explained to the participants as well as its voluntary nature. Those who met the criteria described below and agreed to participate in the study signed an informed consent and completed a set of psychological measures. No financial support or compensation were granted for participation in the study.

Ethics procedures concerning privacy and data protection established by the Portuguese legislation were followed. The study was approved by the Subcommittee on Ethics of Social and Human Sciences of the University XX.

\section{Data analysis}

All the analyses were conducted using the SPSS (Statistical Package for the Social Sciences) Version 27. Descriptive statistics were performed using measures of central and dispersion tendency, and frequencies to describe the sociodemographic and violence-related variables, and intrapersonal characteristics. T-tests and chi-squared testes were used to analyze differences between dropouts and completers. A logistic regression was conducted to identify the variables that best predicted dropout. Finally, the predictive power of the model generated by this procedure was estimated by using the Receiver Operating Characteristic (ROC) analysis. The ROC curve is a graph that plots sensitivity against specificity and thus presents a graphical representation of the trade-off between the positive and negative predictive values at every possible cut-off. The area under the curve (AUC) is used to measure the accuracy of the model. The AUC ranges from .50 and 1, and higher value indicates greater effectiveness of the model. 
Running Head: DROPOUT AMONG IPV PERPETRATORS

\section{Results}

\section{Participation}

Forty-eight of the eighty-three participants completed the intervention program, meaning a completion rate of $57.8 \%$ (and a dropout rate of $42.2 \%$ ). On average, the treatment completers attended more than three-quarters $(M=21.22 ; S D=2.23)$ of the intervention program, meaning the presence on 21 of the 24 core sessions, representing almost 42 hours of treatment (each session varies between 90 to 120 minutes). In contrast, dropouts attended just over a quarter of the intervention program $(M=8.40 ; S D=4.93)$, which equates to eight sessions and 16 hours of treatment. This difference in treatment dosage was highly significant, $t(74)=15.649, p<.001$. The main reasons to abandon the intervention were a failure to attend ( $n=29)$, leave the city or the country $(n=3)$, and illness $(n=3)$.

\section{Characteristics of dropouts and completers}

Table 2 presents the descriptive statistics for both groups on sociodemographic and violencerelated variables. Groups only revealed statistically significant differences in history of previous convictions by other crimes than IPV, $\chi^{2}(1)=6.200, p=.013$, with dropouts presenting more history of previous convictions than completers.

\section{[INSERT TABLE 2 HERE]}

Table 3 displays data for both dropouts and completers in age, relationship length BPAQ total score and subscales, ECVC total score and factors, IRP total score and factors, IVC total score and subscales, and URICA-DV-R Readiness to Change Index and stages of change. Results only showed statistically significant differences between dropouts and completers in age, $t(76)=-2.565, p=.012$, being dropouts younger than dropouts.

\section{[INSERT TABLE 3 HERE]}

\section{Dropout Prediction}


A logistic regression was performed to identify the variables that predict treatment dropout. According to the preliminary findings, two variables were entered in the model (i.e., age, and prior convictions by other crimes than IPV). The results are summarized in Table 4.

\section{[INSERT TABLE 4 HERE]}

The logistic regression model was statistically significant, $\chi^{2}(2)=12.878, p=.002$. According to the pseudo r-square, between $15.2 \%$ (Cox \& Snell) and 20.5\% (Nagelkerke) of the variability was explained by this set of variables. This model classified correctly $69.2 \%$ of all cases. A separate analysis of the variables used in the prediction of treatment dropout made it possible to verify that age $(\mathrm{OR}=.948 ; 95 \% \mathrm{CI}[.906, .991])$ and previous criminal convictions $(\mathrm{OR}=5.647 ; 95 \% \mathrm{CI}[1.335,23.883])$ significantly contribute to the model. Batterers that were younger and with previous criminal convictions were more likely to dropout from intervention. For each unit increase in age, the odds of an IPV's perpetrator to not complete the intervention program decreases by a factor of .948 . Besides, the odds of a batterer to dropout from intervention is 5.647 times higher for those batterers who have previous criminal convictions than for those who have no previous criminal convictions.

The ROC curve analysis revealed that the AUC was .739 $(p<.001 ; 95 \%$ CI $[.622$, $.857])$, which was significantly greater than .50 , meaning that the generated model significantly predict dropout.

\section{Discussion}

This study was designed to increase our understanding about dropout predictors among courtand self-referred batterers who attended a BIP in Portugal. The current work extend previous research on BIPs' dropout by including sociodemographic (e.g., age, marital status, socioeconomic status), violence-related (e.g., criminal record, referral source) and intrapersonal variables (e.g., motivation, aggression, attitudes toward intimate partner 
violence, coping skills). Besides, as far as we know, this is the first study conducted in Portugal assessing variables related to batterers' treatment dropout.

The dropout rate of $42.2 \%$ found in this study is similar to previous studies (e.g., Mach et al., 2017). The high rates of attrition among BIPs are one of the most well known problems since it is associated with an increasing likelihood to re-offend (e.g., Bennett et al., 2007; Carney et al., 2006; Gondolf, 2000; Olver et al., 2011). One possible explanation for the high rates of dropout in the present study is the fact that PPRIAC is free of charge. Literature indicates that when treatment is paid by the individuals, dropout rates tend to decrease (Timko et al., 2015). Another possible explanation is that most of participants were court-mandated. Also, the self-referred ones might enter in treatment as a result of external pressure and did not seek treatment voluntarily (e.g., child protection services; wives' requests to change their behaviours; Eckhardt et al., 2008; Kistenmacher \& Weiss, 2008). Although PPRIAC includes Motivational Interview thecniques (Miller \& Rollnick, 2002), as dropout frequently occurs in the first sessions, participants' lack of motivation and/or engagement in the process of change may lead them to abandon the intervention. Besides, the inconsistent court responses to clients who dropout might be another factor that explains high attrition rates (Adams, 2003). The considerably high rates of attrition lead us to defend that criminal courts should apply sanctions to those who dropout more consistently. This might increase batterers' awareness of the consequences of dropout and therefore increase treatment compliance (Bowen \& Gilchrist, 2006). Also, the creation of specialist domestic violence (DV) courts might be a way to facilitate the early referral of batterers to BIPs and the continuous supervision of men who attend treatment, contributing to prevent dropout. In the US, where specialized courts in DV exist, a significant drop in and higher treatment completion rates were observed (Gondolf, 2000). 
Running Head: DROPOUT AMONG IPV PERPETRATORS

Dropouts were younger and had more previous convictions for other crimes than IPV than completers. Other sociodemographic, violence-related, and intrapersonal variables did not distinguish the groups as reported in previous studies (e.g., Bowen \& Gilchrist, 2006; Cantos et al., 2015; Catlett et al., 2010; Gover et al., 2011; LaPosta et al., 2019; Lauch et al., 2017; Richards et al., 2019). Our results suggest that Portuguese batterers who dropout had a more unstable lifestyle and a low stake in conformity in line with other studies (e.g., Bowen \& Gilchrist, 2006). As Bowen and Gilchrist (2006) referred, these results may "reflect incongruence between the program content and offender's social circumstances” (p. 583). PPRIAC focus on men's attitudes, beliefs and behaviours and men's responsibility in violence against their intimate partners, which might be more compatible with learning styles of participants with a more stable lifestyle, i.e. those who had a more prosocial behaviour (Daly et al., 2001).

As previous studies have found, older batterers tend to complete BIPs more than younger ones (e.g., Askeland \& Heir, 2013; Bowen \& Gilchrist, 2006; Buttell \& Carney, 2008). Perhaps older batterers were more mature (Lauch et al., 2017) and had a greater insight into their problematic behaviour and, as a consequence, perceived treatment more positively and as an opportunity to change their problematic behaviour - the so-called clienttreatment congruence (Bowen \& Gilchrist, 2006). A mismatch between a client's perceived need and the therapy goals are the most cited reasons to abandon intervention (Brown et al., 1997). Older individuals also may be more aware of the implications of their actions, both in terms of impact of their abusive behaviour on victims and in terms of legal consequences associated with the non-completion of the intervention.

Interestingly, the variables that in our study distinguish completers from dropouts are the same that are related both to IPV recidivism (e.g., Cattaneo \& Goodman, 2005; Hanson \& Wallace-Capretta, 2004; Stith et al., 2004) and general recidivism (e.g., Eisenberg et al., 
2019; Gendreau et al., 1996). Individuals who fail to complete intervention programs seem to resemble the generally violent/antisocial group identified by Holtzworth-Munroe and Stuart (1994); i.e., a high-risk group of batterers, as IPV appears in conjunction with a more generalized antisocial behaviour. In fact, studies on batterer typologies also found that generally violent/antisocial perpetrators were more likely to dropout (e.g., Cantos et al., 2015; Mach et al., 2017). Thus, BIPs should be sensitive to these factors, adapting the intervention dosage and tailoring the service supervision to the individuals' characteristics. A batterer would be better served if the treatment program focused its attention to the needs of each individual (Cunha \& Gonçalves, 2013). This is in line with Bonta and Andrews's (2017) principles of risk, need and responsibility that should be considered during the design of intervention programs to maximise intervention effectiveness and reduce attrition rates. It is necessary to match the level of program intensity to offenders' risk level (risk principle), to target offender's needs that are functionally related to criminal behaviour (need principle), and to match the style and mode of intervention to the offender's learning style and abilities (responsivity principle; Andrews et al., 2011). Thus, younger individuals with a prior criminal record might benefit from an intervention with a multimodal and multilevel focus, i.e. promoting batterer's skills and tackling antisocial traits together with IPV specific treatment (Bowen \& Gilchrist, 2006; Cunha \& Gonçalves, 2013), as well as monitoring to keep their adherence to treatment.

The other sociodemographic variables demonstrated absence of relationship with dropout. Although this result differs from most previous studies (e.g., Barber \& Wright, 2010; Catlett et al., 2010; Gover et al., 2011), other authors have found a similar pattern (e.g., Buttell \& Carney, 2002, 2008; Pike \& Buttell, 2002). A possible explanation for these results may be related to cultural differences of the samples (e.g., Buttell \& Carney, 2008). Another admissible explanation may be associated with the intervention program studied and its 
inclusion and exclusion criteria, which might lead to a decrease in sample heterogeneity. At the same time, the inconsistencies found in dropout literature may be related to differences between studies in terms of therapists, programs involved, dropout definitions, treatment settings, and methods used to assess the different constructs (Babcock et al., 2004; Catlett et al., 2010; Cuevas \& Bui, 2016).

About the referral source, no statistically significant differences were found between dropouts and completers. The absence of differences between groups may reflect regional and local differences in the judicial support given to intervention programs (e.g., Buttell \& Carney, 2002; Pike \& Buttell, 2002) and the inconsistent court responses to batterers who dropout (e.g., Babcock \& Taillade, 2000). In regions where judicial support is scarce, there might be a lower probability of legal consequences for the lack of batterers' attendance at the intervention program, resulting in higher dropout rates. Although these inferences do not refer to the Portuguese judicial system, to our knowledge, men who dropout from BIPs did not receive consistent consequences, although the law considers the possibility of suspended prison sentences or provisional suspension processes revocation. Thus, and since the judicial support given to the intervention program may interact with sociodemographic and intrapersonal variables to predict the treatment dropout (e.g., Buttell \& Carney, 2002), this variable should be included in future studies.

Treatment dropouts and completers did not differ in their levels of self-reported violence, attitudes toward IPV, aggression, coping skills and motivation level. The results may be because data included in this study refers to the pre-intervention phase. Thus, considering the inclusion and exclusion criteria, it may be expected that there are no major differences between individuals in this phase of the intervention. Another possible explanation for these results may be related to social desirability. There is evidence that people respond differently to self-report questionnaires when they perceive that their answers 
may have personal (Davis \& Moser, 2014) and possibly legal implications. At the same time, research shows that social desirability may affect the stage of self-reported change by individuals (Zemore, 2012). Thus, the fact that no differences were found in the individuals' motivational stage may be because some reported high levels of change but were not ready to change, or, on the contrary, individuals who initially reported a lower motivation might have increased their desire to change throughout the intervention process. At last, our results revealed that some individuals abandon the intervention program for different reasons (e.g., illness). Therefore, to obtain a more in-depth understanding on the relationship between intrapersonal characteristics and treatment attrition, future studies should explore the explicit reasons for non-compliance (Bowen \& Gilchrist, 2006), as well as other factors that may influence the treatment conclusion (Lauch et al., 2017).

The logistic regression results also supported the role of age and prior convictions in BIPs' dropout. Being younger and having previous convictions by other crimes than domestic violence significantly predicted treatment dropout. However, from the generated model, $31.3 \%$ of batterers were incorrectly classified suggesting that perhaps other variables not studied also play an important role in attrition. For example, external factors to the individual, such as the cost of the sessions, the duration of the program, the distance traveled to participate in the sessions, program curricula, and external monitoring might impact individuals' attendance and/or attrition and should be included in future studies.

Despite the findings, some limitations to this study should be mentioned. First, our sample was small and nonrepresentative, being entirely composed of men from the north of Portugal, and the vast majority was Caucasian. Thus, a larger and more ethnically diverse sample is recommended for future studies. Second, this study refers only to data from one specific intervention program, so it is not possible to generalise these results to other programs. Third, in this study, the variables analysed were mainly assessed through batterers' 
self-report. This may affect the results since literature suggests that batterer's reports are affected by social desirability (Dutton \& Hemphill, 1992). Thus, future research should also include an instrument to assess social desirability. Fourth, the alpha values from some scales (e.g., IRP, BPAQ, URICA-DV-R) were weak which might compromise the results. Finally, variables related to the intervention program (e.g., treatment modality; treatment setting), the therapeutic process (e.g., group cohesion; working alliance), court supervision/monitoring, and social support were not analysed in this study. Thus, future studies should include those factors to understand its impact on treatment dropout and/or compliance (e.g., Jewell \& Wormith, 2010; Olver et al., 2011).

To our knowledge, the current study provides the first insight into the sociodemographic, violence-related, and intrapersonal characteristics of Portuguese batterers who failed to complete a treatment program directed to both court- and self-referred individuals. Our findings corroborate international literature on BIPs' dropout and show that variables that predict attrition are the same that predict IPV and general recidivism. Besides, these results highlight the importance of matching BIPs to offenders' risk, needs and responsivity in order to increase intervention efficacy and treatment compliance.

\section{Data availability statement}

Data available on request from the authors

\section{References}

Adams, D. (2003). Treatment programs for batterers. Clinics in Family Practice, 5, 159-175. Andrews, D. A., Bonta, J., \& Wormith, J. S. (2011). The risk-need-responsivity (RNR) model: Does adding the Good Lives model contribute to effective crime prevention? 
Running Head: DROPOUT AMONG IPV PERPETRATORS

Criminal Justice and Behavior, 28(7), 735-755.

https://doi.org/10.1177/0093854811406356.

Archer, J. (2000). Sex differences in aggression between heterosexual partners: A metaanalytic review. Psychological Bulletin, 126, 651-680. https://doi.org/10.1037/0033$\underline{2909.126 .5 .651}$

Arias, E., Arce, R., \& Vilariño, M. (2013). Batterer intervention programmes: A metaanalytic review of effectiveness. Psychosocial Intervention, 22, 153-160. https://dx.doi.org/10.5093/in2013a18.

Askeland, I. R. \& Heir, T. (2013). Early dropout in men voluntarily undergoing treatment for intimate partner violence in Norway. Violence and Victims, 28(5), 822-831. Doi: https://doi.org/10.1891/0886-6708.VV-D-12-00137.

Babcock, J. C., Graham, K., Canady, B., \& Ross, J. M. (2011). A proximal change experiment testing two communication exercises with intimate partner violent men. Behavior Therapy, 42(2), 336-347. https://doi.org/10.1016/j.beth.2010.08.010.

Babcock, J., Greena, C., \& Robie, C. (2004). Does batterers' treatment work? A metaanalytic review of domestic violence treatment. Clinical Psychology Review, 23, 1023-1053. https://doi.org/10.1016/j.cpr.2002.07.001.

Babcock J., \& Taillade, J. (2000). Evaluating interventions for men who batter. In J. Vincent \& E. Jouriles (eds.), Domestic violence: guidelines for research informed practice. Philadelphia, PA: Jessica Kingsley.

Bacchus, L. J., Ranganathan, M., Watts, C., \& Devries, K. (2018). Recent intimate partner violence against women and health: A systematic review and meta-analysis of cohort studies. BMJ Open. https://doi.org/10.1136/bmjopen-2017-019995.

Barber, S., \& Wright, E. (2010). The effects of referral source supervision. Criminal Justice and Behavior, 37, 847-859. https://doi.org/10.1177/0093854810367771. 
Running Head: DROPOUT AMONG IPV PERPETRATORS

Bennett, L., Stoops, C., Call, C., \& Flett, H. (2007). Program completion and re-Arrest in a batterer intervention system. Research on Social Work Practice, 17, 42-54. https://doi.org/10.1177/1049731506293729.

Blatch, C., O’Sullivan, K., Goodman-Delahunty, J., Willis, M., \& Delaney, J. J. (2020). Effectiveness of a domestic abuse program for Australian indigenous offenders. International Journal of Offender Therapy and Comparative Criminology, 64(16), 1639-1673. https://doi.org/10.1177/0306624X19900979

Bonta, J., \& Andrews, D. (2017). The psychology of criminal conduct (6th ed.). Routledge.

Bowen, E., \& Gilchrist, E. (2006). Predicting dropout of court-mandated treatment in a British sample of domestic violence offenders. Psychology, Crime \& Law, 12, 573587. https://doi.org/10.1080/10683160500337659.

Brown, P. D., O’Leary, K. D., \& Feldbau, S. R. (1997). Dropout in a treatment program for self-referring wife abusing men. Journal of Family Violence, 12, 365-387. https://doi.org/10.1023/A:1021906825073

Buss, A. H., \& Perry, M. (1992). The aggression questionnaire. Journal of Personality and Social Psychology, 63, 452-459. https://doi.org/10.1037//0022-3514.63.3.452.

Buttell, F., \& Carney, M. (2002). Psychological and demographic predictors of attrition among batterers court ordered into treatment. Social Work Research, 26, 31-41. https://doi.org/10.1093/swr/26.1.31.

Buttell, F., \& Carney, M. (2008). A large sample investigation of batterer intervention program attrition: Evaluating the impact of state program standards. Research on Social Work Practice,18, 177-188. https://doi.org/10.1177/1049731508314277.

Buttell, F. P., \& Pike, C. K. (2002). Investigating predictors of treatment attrition among court-ordered batterers. Journal of Social Service Research, 28, 53-68. https://doi.org/10.1300/J079v28n04_03 
Cannon, C., \& Ferreira, R. J. (2017). Understanding female intimate partner violence perpetration, parenting attitudes and batterer intervention program completion. Partner Abuse, 8(3), 272-290. https://doi.org/10.1891/1946-6560.8.3.272

Cannon, C., Hamel, J., Buttell, F., \& Ferreira, R. J. (2016). A survey of domestic violence perpetrator programs in the United States and Canada: Findings and implications for policy and intervention. Partner Abuse, 7(3), 226-276. https://doi.org/10.1891/19466560.7.3.226.

Cantos, A. L., Goldstein, D. A., Brenner, L., O'Leary, K. D., \& Verborg, R. (2015). Correlates and program completion of family only and generally violent perpetrators of intimate partner violence. Behavioral Psychology, 23(3), 549-569.

Carney, M., Buttell, F., \& Muldoon, J. (2006). Predictors of batterer intervention program attrition: Developing and implementing logistic regression models. Journal of Offender Rehabilitation, 43, 35-54. https://doi.org/10.1300/J076v43n02_02.

Cattaneo, L. B., \& Goodman, L. A. (2005). Risk factors for reabuse in intimate partner violence. Trauma, Violence, \& Abuse, 6(2), 141-175. https://doi.org/10.1177/1524838005275088.

Catlett, B., Toews, M., \& Walilko, V. (2010). Men's gendered constructions of intimate partner violence as predictors of court-mandated batterer treatment drop out. AmericanJournal of Community Psychology, 45, 107-123. https://doi.org/10.1007/s10464-009-9292-2

Chang, H., \& Saunders, D. G. (2002). Predictors of attrition in two types of group programs for men who batter. Journal of Family Violence, 17, 273-292. https://doi.org/10.1023/A:1016057328929 
Running Head: DROPOUT AMONG IPV PERPETRATORS

Cheng, S., Davis, M., Jonson-Reid, M., \& Yaeger, L. (2019). Compared to what? A metaanalysis of batterer intervention studies using nontreated controls or comparisons. Trauma, Violence, \& Abuse. https://doi.org/10.1177/1524838019865927.

Cissner, A. B., \& Puffett, N. K. (2006). Do batterer program length or approach affect completion or re-arrest rates? A comparison of outcomes between defendants sentenced to two batterer programs in brooklyn. Center for Court Innovation. https://www.courtinnovation.org/sites/default/files/IDCC\%20DCAP\%20final\%20.pd f

Coulter, M., \& VandeWeerd, C. (2009). Reducing domestic violence and other criminal recidivism: Effectiveness of a multilevel batterers intervention program. Violence and Victims, 24, 139-152. https://doi.org/10.1891/0886-6708.24.2.139.

Cuevas, D., \& Bui, N. (2016). Social factors affecting the completion of a batterer intervention program. Journal of Family Violence, 31, 95-107. https://doi.org/10.1007/s10896-015-9748-0.

Cunha, O., \& Gonçalves, R. A. (2013). Intimate partner violence offenders: Generating a data-based typology of batterers and implications for treatment. The European Journal of Psychology Applied to Legal Context, 5, 131-139. https://doi.org/10.5093/ejpalc2013a2.

Cunha, O., \& Gonçalves, R. A. (2014). The current practices of intervention with batterers. Revista de Psiquiatria Clínica, 41, 40-48. https://doi.org/10.1590/010160830000000008.

Cunha, O., \& Gonçalves, R. A. (2015). Efficacy assessment of an intervention program with batterers. Small Group Research, 46, 455-482. https://doi.org/10.1177/1046496415592478. 
Running Head: DROPOUT AMONG IPV PERPETRATORS

Dalton, B. (2001). Batterer characteristics and treatment completion. Journal of Interpersonal Violence, 16, 1223-1238. https://doi.org/10.1177/088626001016012001.

Dalton, B. (2007). What's going on out there? A survey of batterer intervention programs. Journal of Aggression, Maltreatment \& Trauma, 15, 59-74. https://doi.org/10.1300/J146v15n01_04.

Daly, J., \& Pelowski, S. (2000). Predictors of dropout among men who batter: A review of studies with implications for research and practice. Violence and Victims, 15, 137160. https://doi.org/10.1891/0886-6708.15.2.137.

Daly, J. E., Power, T., \& Gondolf, E. W. (2001). Predictors of batterer program attendance. Journal of Interpersonal Violence, 16, 971-991. https://doi.org/10.1177/088626001016010001.

Davis, C., \& Moser, S. (2014). Social desirability and change following substance abuse treatment in male offenders. Psychology of Addictive Behaviors, 28, 872-879. https://doi.org/10.1037/a0037528

DeHart, D. D., Kennedy, R. J., Burke, L. K., \& Follingstad, D. R. (1999). Predictors of attrition in a treatment program for battering men. Journal of Family Violence, 14(1),19-34. http://dx.doi.org/10.1023/A:1022861809014

Dutton, D. G., \& Hemphill, K. J. (1992). Patterns of socially desirable responding among perpetrators and victims of wife assault. Violence and Victims, 7, 29-39. https://doi.org/10.1891/0886-6708.7.1.29

Eckhardt, C., Holtzworth-Munroe, A., Norlander, B., Sibley, A., \& Cahill, M. (2008). Readiness to change, partner violence subtypes, and treatment outcomes among men in treatment for partner assault. Violence and Victims, 23, 446-475. https://doi.org/10.1891/0886-6708.23.4.446. 
Eisenberg, M., J., van Horn, J. E., Dekker, J. M., Assink, M., van der Put, C. E., Hendriks, J., \& Stams, G. J. J. M. (2019). Static and Dynamic predictors of general and violent recidivism in the forensic outpatient population: A meta-analysis. Criminal Justice and Behavior, 10. https://doi.org/10.1177/0093854819826109

Feder, L., \& Wilson, D. (2005). A meta-analytic review of court-mandated batterer intervention programs: Can courts affect abusers' behavior? Journal of Experimental Criminology, 1, 239-262. https://doi.org/10.1007/s11292-005-1179-0

Ferrer-Perez, V., \& Bosch-Fiol, E. (2016). Batterer intervention programs in Spain: An analysis of their effectiveness. International Journal of Offender Therapy and Comparative Criminology, 62, 1-13. https://doi.org/10.1177/0306624X16672455

Gendreau, P., Little, T., \& Goggin, C. (1996). A meta-analysis of the predictors of adult offender recidivism: What works! Criminology, 34(4), 575-607. https://doi.org/10.1111/j.1745-9125.1996.tb01220.x

Gondolf, E. W. (2000). A 30-month follow-up of court-refered batterers in four cities. International Journal of Offender Therapy and Comparative Criminology, 44, 11-128. https://doi.org/10.1177/0306624X00441010

Gondolf, E. W., \& Foster, R. A. (1991). Preprogram attrition in batterers programs. Journal of Family Violence, 6, 337-349. https://doi.org/10.1007/BF00980537

Gover, A., Jennings, W., Davis, C., Tomsich, E., \& Tewksbury, R. (2011). Factors related to the completion of domestic violence offender treatment: The Colorado experience. Victims \& Offenders: An International Journal of Evidence-based Research, Policy, and Practice, 6, 137-156. https://doi.org/10.1080/15564886.2011.557323.

Hanson, R. K., \& Wallace-Capretta, S. (2004). Predictors of criminal recidivism among male batterers. Psychology, Crime \& Law, 10(4), 413-427. https://doi.org/10.1080/10683160310001629283. 
Running Head: DROPOUT AMONG IPV PERPETRATORS

Holtzworth-Munroe, A., \& Stuart, G. L. (1994). Typologies of male batterers: Three subtypes and the differences among them. Psychological Bulletin, 116, 476-497. https://doi.org/10.1037/0033-2909.116.3.476.

Jewell, L., \& Wormith, J. (2010). Variables associated with attrition from domestic violence treatment programs targeting male batterers: A meta-analysis. Criminal Justice and Behavior, 37, 1086-1113. https://doi.org/10.1177/0093854810376815.

Karakurt, G., Koç, E., Çetinsaya, E. E., Ayluçtarhan, Z., \& Bolen, S. (2019). Meta-analysis and systematic review for the treatment of perpetrators of intimate partner violence. Neuroscience and Biobehavioral Reviews, 150, 220-230. https://doi.org/10.1016/j.neubiorev.2019.08.006.

Kistenmacher, B. R., \& Weiss, R. L. (2008). Motivational interviewing as a mechanism for change in men who batter: A randomized controlled trial. Violence and Victims, 23, 558-570. https://doi.org/10.1891/0886-6708.23.5.558.

LaPosta, G. M. P., Creech, S. K., Macdonald, A., \& Taft, C. T. (2019). Predictors of session attendance in intimate partner violence treatment for trauma-exposed veterans. Partner Abuse, 10(3), 283-297. https://doi.org/10.1891/1946-6560.10.3.283

Lauch, K., Hart, K., \& Bresler, S. (2017). Predictors of treatment completion and recidivism among intimate partner violence offenders. Journal of aggression, maltreatment \& trauma, 26, 543-557. https://doi.org/10.1080/10926771.2017.1299824

Levesque, D. A., Gelles, R., Velicer, W. F. (2000). Development and validation of a stages of change measure for men in batterer treatment. Cognitive Therapy and Research, 24(2), 175-199. https://doi.org/10.1023/A:1005446025201.

Lila, M., Gracia, E., \& Catalá-Miñana, A. (2018). Individualized motivational plans in batterer intervention programs: A randomized clinical trial. Journal of Consulting and Clinical Psychology, 86(4), 309-320. https://doi.org/10.1037/ccp0000291. 
Lila, M., Gracia, E., \& Catalá-Miñana, A. (2020). More likely to dropout, but what if they don't? Partner violence offenders with alcohol abuse problems completing batterer intervention programs. Journal of Interpersonal Violence, 35(9-10), 1958-1981. https://doi.org/10.1177/0886260517699952.

Lila, M., Martín-Fernández, M., Gracia, E., López-Ossorio, J., \& González, J. L. (2019). Identifying key predictors of recidivism among offenders attending a batterer intervention program: A survival analysis. Psychosocial Intervention, 28(3), 157-167. https://doi.org/10.5093/pi2019a19.

Mach, J., Cantos, A., Weber, E., \& Kosson, D. (2017). The impact of perpetrator characteristics on the completion of a partner abuse intervention program. Journal of Interpersonal Violence, 1-27. https://doi.org/10.1177/0886260517719904.

Machado, C., Gonçalves, M. M., \& Matos, M. (2007). Manual do inventário de violência conjugal (IVC) e da escala de crenças de violência conjugal (ECVC) [Marital Violence Inventory (IVC) and Attitudes Toward Marital Violence Scale (ECVC) manual]. Psiquilíbrios Edições.

Manita, C. (2008). Programas de intervenção em agressores de violência conjugal. Intervenção psicológica e prevenção da violência doméstica [Intervention programs in domestic violence offenders: Domestic violence psychological intervention and prevention]. Ousar Integrar - Revista de Reinserção Social e Prova, 1, 21-32.

Marques, T., Batista, M., \& Costa, S. (2019, May 23-24). O programa CONTIGO em Cascais: Aplicação e resultados [The CONTIGO program in Cascais: Aplication and results] [Paper presentation]. I Encontro Violência Doméstica: Um olhar sobre agressores, Cascais, Portugal. 
Running Head: DROPOUT AMONG IPV PERPETRATORS

McMurran, M., Huband, N., \& Overton, E. (2010). Non-completion of personality disorder treatments: A systematic review of correlates, consequences, and interventions. Clinical Psychology Review, 30, 277-287. https://doi.org/10.1016/j.cpr.2009.12.002

Miller, R. M., \& Rollnick, S. (2002). Motivational interviewing, preparing people for change (2nd ed.). Guilford Press.

Olver, M., Wormith, J., \& Stockdale, K. (2011). A meta-analysis of predictors of offender treatment attrition and its relationship to recidivism. Journal of Consulting and Clinical Psychology, 79, 6-21. https://doi.org/10.1037/a0022200

Pearson, D. A. S., Steward, C. D. \& Ford, A. K. (2020). Client retention in community treatment: Completer and noncompleter experiences of an individualized, needs-based partner abuse intervention program. Journal of Interpersonal Violence. https://doi.org/10.1177/0886260520907356

Pike, C., \& Buttell, F. (2002). Investigating predictors of treatment attrition among courtordered batterers. Journal of Social Service Research, 28, 53-68. https://doi.org/10.1300/J079v28n04_03.

Priester, M. A., Kulkarni, S., Mennicke, A., \& Bell, B. A. (2019). Factors associated with batterer intervention program attrition. Violence and Victims, 34(2), 296-311. https://doi.org/10.1891/0886-6708.VV-D-17-00067.

Quintas, J., Fonseca, E. P., Sousa, H., \& Serra, A. (2012). Programa para agressores de violência doméstica: Avaliação do impacto da aplicação experimental (2010-2011) [Program for domestic violence offenders: Impact assessment of an experimental aplication]. Ousar Integrar - Revista de Reinserção Social e Prova, 12, 9-26.

Richards, T. N., Jennings, W. G., \& Murphy, C. (2019). Risk and protective factors for batterer intervention treatment program attrition: How completers are distinct from 
Running Head: DROPOUT AMONG IPV PERPETRATORS

dropouts and no-shows. Journal of Interpersonal Violence, 1-20.

https://doi.org/10.1177/0886260519834096.

Rijo, D., \& Capinha, M. (2012). A reabilitação dos agressores conjugais: Dos modelos tradicionais de reabilitação ao Programa Português para Agressores de Violência Doméstica (PAVD) [Marital offenders' rehabilitation: From traditional rehabilitation models to the Portuguese program for domestic violence offenders]. Ousar IntegrarRevista de Reinserção Social e Prova, 11, 83-97.

Romero-Martínez, A., Lila, M., Gracia, M., \& Moya-Albiol, L. (2019). Dropout from courtmandated intervention programs for intimate partner violence offenders: The relevance of alcohol misuse and cognitive impairments. International Journal of Environmental Research and Public Health, 16(13), 2402. https://doi.org/10.3390/ijerph16132402

Rooney, J., \& Hanson, R. K. (2001). Predicting attrition from treatment programs for abusive men. Journal of Family Violence, 16, 131-149. https://doi.org/10.1023/A:1011106902465

Santirso, F., Gilchrist, G., Lila, M., \& Gracia, E. (2020). Motivational strategies in interventions for intimate partner violence offenders: A systematic review and metaanalysis of randomized controlled trials. Psychosocial Intervention, 29(3), 175-190. https://doi.org/10.5093/pi2020a13

Scott, K., King, C., McGinn, H., \& Hosseini, N. (2011). Effects of motivational enhancement on immediate outcomes of batterer intervention. Journal of Family Violence, 26, 139- 149. https://doi.org/10.1007/s10896-010-9353-1.

Serra, A. V. (1987). Um estudo sobre coping: O inventário de resolução de problemas [A coping study: The problema solving inventory]. Psiquiatria Clínica, 9, 301-316. 
Running Head: DROPOUT AMONG IPV PERPETRATORS

Sistema de Segurança Interna (2020). Relatório anual de segurança interna 2019 [Internal security anual report]. https://www.portugal.gov.pt/downloadficheiros/ficheiro.aspx?v=19cabc8c-e3f1-4cb2-a491-a10c8a3e4bf0

Stith, S.M., Smith, D.B., Penn, C., Ward, D., \& Tritt, D. (2004). Intimate partner physical abuse perpetration and victimization risk factors: A meta-analytic review. Journal of Aggression and Violent Behavior, 10, 65-

98.https://doi.org/10.1016/j.avb.2003.09.001.

Straus, M. A. (2011). Gender symmetry and mutuality in perpetration of clinicallevel partner violence: Empirical evidence ad implications for prevention and treatment. Aggression and Violent Behavior, 16, 279-288. https://doi.org/10.1016/j.avb.2011.04.010

Timko, C., Valenstein, H., Stuart, G., \& Moos, R. (2015). Substance abuse and batterer programmes in California, USA: factors associated with treatment outcomes. Health and Social Care in the Community, 23, 642-653. https://doi.org/10.1111/hsc.12178.

Vilariño, M., Amado, B. G., Vázquez, M. J., \& Arce, R. (2018). Psychological harm in women victims of intimate partner violence: Epidemiology and quantification of injury in mental health markers. Psychosocial Intervention, 27(3), 145-152. https://doi.org/10.5093/pi2018a23

World Health Organization [WHO] (2012). Understanding and addressing violence against women. https://apps.who.int/iris/bitstream/handle/10665/77432/WHO_RHR_12.36_eng.pdf

Zemore, S. (2012). The effect of social desirability on reported motivation, substance use severity, and treatment attendance. Journal of Substance Abuse Treatment, 42, 400412. https://doi.org/10.1016/j.jsat.2011.09.013 
Running Head: DROPOUT AMONG IPV PERPETRATORS

Table 1

Sociodemographic and Violence-Related Variables

\begin{tabular}{lll}
\hline & $\mathbf{N}$ & \% \\
\hline Marital status & & 49.4 \\
Married/in cohabitation & 41 & 47 \\
Not married/not in cohabitation & 39 & \\
\hline Educational level & & 27.7 \\
$4^{\text {th }}$ grade & 23 & 24.1 \\
$6^{\text {th }}$ grade & 20 & 20.5 \\
$9^{\text {th }}$ grade & 17 & 21.7 \\
$12^{\text {th }}$ grade/College & 18 & \\
\hline
\end{tabular}

Socioeconomic status

Low $\quad 39$

Medium/High

40

48.2

\section{Ethnicity}

Caucasian

82

98.8

Black

1

1.2

Professional status

Active

Inactive

42

50.6

Prior convictions

Yes

12

14.5

No

71

85.5

Prior convictions by IPV

Yes

4

No

77

92.8

Referral source

Court-referred

Self-referred 
Running Head: DROPOUT AMONG IPV PERPETRATORS

Table 2

Differences Between Dropouts and Completers on Sociodemographic and Violence-Related Variables

\begin{tabular}{|c|c|c|c|c|c|c|}
\hline & $\begin{array}{c}\text { Dropouts } \\
\text { M (SD) }\end{array}$ & $\begin{array}{l}\text { Completers } \\
\text { M (SD) }\end{array}$ & $t$ & $p$ & $95 \% C I$ & $d$ \\
\hline Age & $42.44(11.94)$ & $49.13(10.89)$ & -2.523 & .012 & {$[-11.89,-1.50]$} & .59 \\
\hline Relationship length & $17.70(11.96)$ & $19.97(12.53)$ & -.773 & .442 & {$[-8.15,3.60]$} & - \\
\hline IVC Total & $8.74(6.67)$ & $9.44(7.32)$ & -.443 & .659 & {$[-3.81,2.43]$} & \\
\hline Physical & $4.80(5.62)$ & $5.41(5.63)$ & -.404 & .688 & {$[-3.62,2.40]$} & \\
\hline \multirow[t]{2}{*}{ Psychological } & $5.28(2.88)$ & $5.78(3.97)$ & -.532 & .597 & {$[-2.39,1.39]$} & \\
\hline & $\begin{array}{c}\text { Dropouts } \\
\mathbf{N}(\%) \\
\end{array}$ & $\begin{array}{l}\text { Completers } \\
\qquad \mathrm{N}(\%) \\
\end{array}$ & $\chi^{2}$ & $p$ & Cramer V & \\
\hline \multicolumn{7}{|l|}{ Marital status } \\
\hline $\begin{array}{l}\text { Married/in } \\
\text { cohabitation }\end{array}$ & $17(51.5)$ & $24(51.1)$ & .002 & .574 & - & \\
\hline $\begin{array}{l}\text { Not married/not } \\
\text { in cohabitation }\end{array}$ & $16(48-5)$ & $23(48.9)$ & & & & \\
\hline
\end{tabular}

Educational level

\begin{tabular}{|c|c|c|c|c|}
\hline $4^{\text {th }}$ grade & $8(25)$ & $15(32.6)$ & & \\
\hline $6^{\text {th }}$ grade & 7 (21.9) & $13(28.3)$ & 2.241 & .524 \\
\hline $9^{\text {th }}$ grade & 7 (21.9) & $10(21.7)$ & & \\
\hline $12^{\text {th }}$ grade/College & $10(31.3)$ & $8(17.4)$ & & \\
\hline
\end{tabular}

SES

$\begin{array}{lllll}\text { Low } & 16(48.5) & 23(50.0) & .018 \quad .534\end{array}$

Medium/High $\quad 17(51.5) \quad 23(50.0)$

Professional status

$\begin{array}{llll}\text { Active } & 14(40.0) & 27(56.3) & 2.138 \quad .107\end{array}$

Inactive $\quad 21(60.0) \quad 21(43.8)$

Prior convictions

$6.200 \quad .013$

.273 
Running Head: DROPOUT AMONG IPV PERPETRATORS

\begin{tabular}{|c|c|c|c|c|c|}
\hline Yes & $9(25.7)$ & $3(6.3)$ & & & \\
\hline No & $26(74.3)$ & $45(93.8)$ & & & \\
\hline \multicolumn{6}{|l|}{ IPV prior } \\
\hline \multicolumn{6}{|l|}{ convictions } \\
\hline Yes & $3(8.8)$ & $1(2.1)$ & 1.884 & $.1 / 0$ & $\begin{array}{ll}- & - \\
\end{array}$ \\
\hline No & $31(91.2)$ & $46(97.9)$ & & & \\
\hline \multicolumn{6}{|l|}{ Referral source } \\
\hline Court-referred & $23(65.7)$ & $31(64.1)$ & .011 & .552 & - \\
\hline Self-referred & $12(34.3)$ & $17(35.4)$ & & & \\
\hline
\end{tabular}

Note. IVC = Marital Violence Inventory. 
Running Head: DROPOUT AMONG IPV PERPETRATORS

Table 3

Differences Between Dropouts and Completers on Intrapersonal Variables

\begin{tabular}{|c|c|c|c|c|c|}
\hline & Dropouts & Completers & \multirow{2}{*}{$t$} & \multirow{2}{*}{$p$} & \multirow{2}{*}{$95 \% C I$} \\
\hline & M (SD) & M (SD) & & & \\
\hline URICA RCI & $38.62(12.87)$ & $35.66(12.46)$ & 1.047 & .296 & {$[-2.63,7.04]$} \\
\hline URICA PC & $12.70(4.28)$ & $13.43(3.45)$ & -.785 & .435 & {$[-2.57,1.12]$} \\
\hline URICA C & $19.03(5.44)$ & $17.28(5.28)$ & 1.362 & .178 & {$[-.82,4.33]$} \\
\hline URICA A & $20.43(4.93)$ & $19.08(4.71)$ & 1.170 & .246 & {$[-.96,3.68]$} \\
\hline URICA M & $12.03(4.63)$ & $12.50(5.29)$ & -.385 & .701 & {$[-2.89,1.95]$} \\
\hline BPAQ Total & $62.83(16.10)$ & $62.44(15.24)$ & .113 & .911 & {$[-6.51,7.29]$} \\
\hline BPAQ PA & $18.36(5.40)$ & $16.05(5.30)$ & 1.731 & .088 & {$[-.35,4.96]$} \\
\hline BPAQ VA & $12.03(3.39)$ & $12.10(2.86)$ & -.086 & .931 & {$[-1.55,1.42]$} \\
\hline BPAQ A & $14.86(5.17)$ & $15.34(5.25)$ & -.379 & .706 & {$[-3.01,2.05]$} \\
\hline BPAQ H & $17.33(5.45)$ & $18.18(4.72)$ & -.380 & .492 & {$[-3.27,1.59]$} \\
\hline ECVC Total & $88.03(27.17)$ & $90.90(22.19)$ & -.529 & .599 & {$[-13.66,7.93]$} \\
\hline ECVC F1 & $24.57(8.65)$ & $26.15(7.42)$ & -.890 & .388 & {$[-5.09,1.95]$} \\
\hline ECVC F2 & $27.09(9.36)$ & $28.13(7.14)$ & -.574 & .568 & {$[-4.64,2.56]$} \\
\hline ECVC F3 & $27.54(7.36)$ & $27.56(6.68)$ & -.013 & .990 & {$[-3.10,3.06]$} \\
\hline ECVC F4 & $8.83(3.62)$ & $9.06(3.08)$ & -.318 & .752 & {$[-1.70,1.23]$} \\
\hline IRP Total & $141.83(16.11)$ & $141.54(13.89)$ & .087 & .931 & {$[-6.29,6.86]$} \\
\hline IRP F1 & $16.00(3.65)$ & $15.27(3.46)$ & .927 & .357 & {$[-.84,2.30]$} \\
\hline IRP F2 & $23.49(3.54)$ & 23.67 (3.79) & -.221 & .826 & {$[-1.81,1.45]$} \\
\hline IRP F3 & $12.09(2.73)$ & $11.92(3.02)$ & .262 & .794 & {$[-1.11,1.45]$} \\
\hline IRP F4 & $29.46(5.39)$ & $28.58(5.22)$ & .743 & .460 & {$[-1.47,3.21]$} \\
\hline
\end{tabular}


Running Head: DROPOUT AMONG IPV PERPETRATORS

\begin{tabular}{cccccc}
\hline IRP F5 & $15.77(3.20)$ & $15.69(3.35)$ & .115 & .909 & {$[-1.37,1.54]$} \\
IRP F6 & $11.20(1.91)$ & $11.42(1.41)$ & -.595 & .553 & {$[-.94, .51]$} \\
IRP F7 & $9.26(1.38)$ & $9.29(1.43)$ & -.110 & .912 & {$[-.66, .59]$} \\
IRP F8 & $13.66(2.95)$ & $14.81(3.25)$ & -1.663 & .100 & {$[-2.54, .23]$} \\
IRP F9 & $10.91(2.09)$ & $10.90(2.33)$ & .037 & .970 & {$[-.97,1.01]$} \\
\hline
\end{tabular}

Note. URICA RCI = University of Rhode Island Change Assessment Scale-Domestic

Violence Readiness of Change Index; URICA PC $=$ Precontemplation; URICA C $=$

Contemplation; URICA A = Action; URICA M = Maintenance; BPAQ = Buss-Perry

Aggression Questionnaire; BPAQ PA = Physical Aggression; BPAQ VA = Verbal

Aggression; BPAQ A = Anger; BPAQ H = ire Hostility; ECVC = Attitudes Toward Marital

Violence Scale; ECVC F1 = Legitimation and Minimization of Minor Violence, ECVC F2 = Legitimation of Violence Due to Women's Behavior; ECVC F3 = Legitimation of Violence

Due to External Causes; ECVC F4 = Legitimation of Violence Due to Family Privacy; IRP = Problem-Solving Inventory; IRP F1 = Request for Help; IRP F2 = Confrontation and Active Problem Solving; IRP F3 = Passive Abandonment at the Situation; IRP F4 = Internal/External Control of the Problems; IRP F5 = Strategies of Emotions' Control; IRP F6 = Active Attitude of Non-Interference in Everyday Life by Occurrences; IRP F7 = Internalized/Externalized Aggression; IRP F8 = Self-Accountability and Fear of Consequences; IRP F9 = Confronting the Problems and Planning Strategies. 
Running Head: DROPOUT AMONG IPV PERPETRATORS

Table 4

Logistic Regression Model Predicting Dropout

95\% C.I. para $\operatorname{EXP}(B)$

\begin{tabular}{lccccccc} 
& B & S.E. & Wald & $\mathbf{p}$ & $\operatorname{Exp}(\mathbf{B})$ & $\mathbf{L}$ & H \\
\hline Age & -.054 & .023 & 5.510 & .019 & .948 & .906 & .991 \\
Prior convictions & 1.731 & .736 & 5.536 & .019 & 5.647 & 1.335 & 23.883 \\
Constant & 1.829 & 1.056 & 3.002 & .083 & 6.227 & &
\end{tabular}

Note. $\mathrm{CI}=$ confidence interval. 